2. Rand CM, Patwari PP, Rodikova, et al. Rapid-onset obesity with hypothalamic dysfunction, hypoventilation, and autonomic dysregulation: analysis of hypothalamic and autonomic candidate genes. Pediatr Res. 2011; 70:375-8.

3. Bougneres $P$, Pantalone $L$, et al. Endocrine manifestations of the rapid-onset obesity with hypoventilation, hypothalamic, autonomic dysregulation, and neural tumor syndrome. J Clin Endocrinol Metab. 2008; 93:3971-80.

\section{P250 IMPROVING E-LEARNING ENVIRONMENTS FOR TOMORROW'S PAEDIATRICIANS}

${ }^{1,2}$ Elizabeth Larkin*, ${ }^{1,2}$ Katie O'Connor, ${ }^{1,2}$ Paul McNally. ${ }^{1}$ The Royal College of Surgeons Ireland, Dublin, Ireland; ' Our Lady's Children's Hospital Crumlin, Dublin, Ireland

\subsection{6/archdischild-2019-epa.600}

Introduction Students presently rely on the internet both as a data source and for educational needs; therefore, medical education should embrace changes in the learning landscape in light of technological advancements [1]. The RCSI Paediatrics undergraduate programme utilises an e-learning platform to support and reinforce didactic teaching.

A quality audit of RCSI's Paediatric e-learning platform was conducted 2015 to 2018 . In 2015, 75\% of students surveyed reported poor platform accessibility, difficulty finding the desired information, and out-dated content.

Aim To identify effective ways of utilising an e-learning platform and improve support for learning and teaching online.

Methods Students were surveyed $(n=330)$ and stakeholder meetings $(n=20)$ were conducted to discuss and better understand our learners and their learning needs. User reports from the e-learning platform indicated changes in users' frequency of access and duration online.

Results Feedback in 2015 showed student engagement and satisfaction were poor. To address this problem, students were surveyed and asked to identify aspects of the e-learning environment they liked and which could be improved.

Effort were made to identify e-learning platform areas requiring attention. By 2018 following implementation of platform improvements, there was a $79 \%$ increase in student visits.

Improvements included usability, making the e-learning platform layout and organisation more user friendly; compatibility, improving compatibility across interfaces for better access on mobile devices; diversity, creating multimedia content allowing users to select the media options that best suit their learning needs; medical educational videos, created to demonstrate how to conduct a physical exam, take patient history, and communicate and interact with patients and their parents; and selfdirected learning, students take increasing responsibility for their learning [2]. Gaining independent learning skills aid students in becoming lifelong, self-directed learners [3].

Conclusion This audit aimed to improve medical students' user experience and create a helpful e-learning environment to prepare future paediatricians. The 2018 user reports and student feedback showed greater student satisfaction and higher e-learning engagement.

\section{REFERENCES}

1. Ruiz JG, Mintzer MJ, Leipzig RM. The impact of e-learning in medical education. Academic medicine. 2006 Mar 1;81(3):207-12.

2. Jasper MA. The potential of the professional portfolio for nursing. J Clin Nurs 1995:4:249-55.

3. Morris, A. P., Highet, L. J, and Frazer S. E (2010) Using ePortfolios to support clinical training in paediatrics. Arch Dis Child Educ Pract Ed 2010;95:157-164. doi:10.1136/158 adc.2008.142265

\section{P251 IT'S A KNOCK OUT! - DENTAL TRAUMA}

Emma O'Donnell, Victoria Cave, Niamh McGrath*. Glasgow Dental Hospital, Glasgow, UK

\subsection{6/archdischild-2019-epa.601}

Introduction By 14 years of age, 30\% of children have experienced a dental injury (1). Sports-related accidents account for $10-39 \%$ of all dental injuries(2). Wearing a properly fitted mouthguard during high risk sports has been shown to significantly reduce the risk of dental injury (3). In the United Kingdom, for many high risks sports mouthguard wear is still not compulsory. As a result, participants are at significant risk of traumatic dental injury. One of the more serious dental injuries is an Avulsion. This often results in multiple appointments over years, missing many days of work and school and a cost burden to the NHS. The average total cost of treating one patient with one traumatic injury has been cited as $£ 856(4)$. It is known that immediate management of this kind of dental injury is critical for improved outcomes. We therefore proposed 'It's a Knock Out!' project.

Aims Improve dental trauma outcomes via improving knowledge and education of dental trauma prevention and management in higher risk groups. Subsequently aims included expansion of the training sessions out with Greater Glasgow.

Method Questionnaires were given before and after a presentation, practical and prevention session. These were aimed at educating non-dental care givers including coaches and management of sporting teams, youth groups and higher P.E Student. Posters and leaflets were donated as memory aids. Local dental contacts were made in case of trauma.

Results Initial knowledge of management was poor. Attendees found the practical training most useful. Knowledge regarding time limits and who to attend was improved on. We received positive feedback from all groups approached. The attendees were more confident in dealing with dental avulsion.

\section{REFERENCES}

1. Management of Dental Trauma in a Primary Care Setting by Martha Ann Keels accessed on: http://pediatric.aappublications.org/content/133/2/e466

2. American Academy of Pediatric Dentistry. Policy on prevention of sports-related orofacial injuries. Pediatric Dent. 2012/2013;34(6):67-70

3. Fernandes LM, Neto JCL, Lima TFR, et al. The use of mouthguards and prevalence of dento- alveolar trauma among athletes: A systematic review and meta analysis. Dent Traumatol. 2019;35:54-72. https://doi org/10.1111/edt.12441

4. The cost of treating children and adolescents with injuries to their permanent incisors at a dental hospital in the United Kingdom, Ferranti S. L. Wong; Konstantina Kolokotsa, 02 November 2004 accessed on:

\section{P252 STUDENT AND TEACHER EXPERIENCE OF CASE-BASED E-LEARNING IN PAEDIATRICS}

${ }^{1}$ Sarah Lewis*, ${ }^{2}$ Eoin Fitzgerald, ${ }^{1}$ Niall Collins, ${ }^{2}$ Katie Flinn, ${ }^{1,2}$ Clodagh O'Gorman, ${ }^{2}$ AnneMarie Murphy. 'University of Limerick, Limerick, Ireland; '2University Hospital Limerick, Limerick, Ireland

\subsection{6/archdischild-2019-epa.602}

Introduction Case-based learning teaches clinical reasoning, while the online environment allows flexibility of access and encourages self-directed learning. The use of virtual patients allows students to experience clinical decision-making in a safe environment and to learn about rare clinical presentation. Our aim was to explore the feasibility of designing a self-directed, case-based online learning module for undergraduate medical students in paediatrics. 
Methods Clinical cases were selected from paediatric admissions to University Hospital Limerick, with written informed consent obtained from parents for use of their child's clinical information. Of several E-learning course development applications reviewed, 'Articulate' was selected for its ease of use, capacity to design interactive components, ability to incorporate multimedia and aesthetics. The course framework was created by our I.T. officer and clinical data and supporting content were added by the clinical tutors.

Results Our pilot case followed the clinical course of an infant with pyloric stenosis from presentation to outcome and was completed by medical students at the end of their paediatric rotation. Twenty-three students completed an anonymous online questionnaire on their experience of the course.

The visual aspects of the course were rated as very high quality by $87 \%$ of students and high quality by $13 \%$. Ease of navigation was rated as extremely easy by $69 \%$, with $96 \%$ of students satisfied with the duration of the course. Of students surveyed, $78 \%$ were happy with the level of interactivity, while $21 \%$ of students would have liked additional interactive sections.

The course was described as 'extremely useful' by $56 \%$ of students and 'very useful' by $30 \%$, with only $4 \%$ finding the course 'not very useful'. All students reported learning new information, with $17 \%$ learning 'a great deal', 39\% 'a lot' and $39 \%$ a 'moderate amount' of information. Of those surveyed, $78 \%$ reported they 'definitely would' and $21 \%$ that they 'probably would' access more cases.

The 'Articulate' software allowed both I.T. and clinical tutors to contribute to the design process and cost was acceptable, with funding agreed by the university.

Conclusion We have successfully designed an authentic interactive case-based E-learning course with excellent feedback from medical students. We plan to demonstrate evidence of objective learning through formal assessment and to create more cases in keeping with the undergraduate paediatric teaching curriculum. We hope to design cases of increased complexity which could be extended to postgraduate paediatric trainees.

\section{P253 HOW MUCH IS TOO MUCH? SKY ROCKETING COST OF CONTINUOUS PROFESSIONAL DEVELOPMENT}

Shashwat Saran*. Shropshire Community health NHS Trust, Shrewsbury, UK

\subsection{6/archdischild-2019-epa.603}

Background Continuous Professional Development (CPD) is a mandatory requirement for revalidation. Financial constraints due to austerity have consistently upset study budgets. The high cost of CPD is a deterrent in the professional growth and may, in turn, impact the quality of patient care. The author efficaciously organised a multi-agency CPD event at an all-inclusive cost of $£ 40$.

Objective To explore an alternative way of coping with the ever-rising cost of CPD's!

Methods Participants in a well-attended multi-agency safeguarding CPD event in England were surveyed. Out of 130 participants, 119 contributed to the survey. The response rate was over $90 \%$.

Results $70 \%$ of the responders were from Health, $16 \%$ from Education, 12\% from Children's Social Care and 2\% from the Police department.
From the health side, $60 \%$ were Consultants, 27\% were Paediatric trainees, 10\% were Nurses and 3\% were GPs.

1 in 2 responders had no specific study budget. 1 in 3 had a study budget of between $£ 500$ and $£ 1000$. 1 in 10 of them was allowed to spend less than $£ 500$ and 1 in 20 had the luxury to spend $£ 1000$ per year.

2 out of 3 of the respondents reported that their study budget is inadequate. An overwhelming majority (80\%) were of the opinion that the CPD events should either be free to attend or cost less than $£ 50$ per day.

Conclusion Many CPD events are currently priced at $£ 500$ or more. Attending one such CPD may consume entire year's study budget and seriously jeopardise clinicians ability to keep up with the on-going learning needs in a fast-changing world of medicine. Tax Payers' money must not be used for institutional profiteering.

Recommendations We strongly suggest rationalising and optimising the cost of the CPD events and putting up a cap on the maximum amount of money that could be charged.

\section{P254 COMPARING THE OPINION OF TRAINEE DOCTORS AND CONSULTANTS WITH REGARDS A TRAINEE'S PREPAREDNESS FOR PAEDIATRIC WORK}

1,2,3Paddy McCrossan*, 'Naomi McCallion. 'Royal College of Surgeons in Ireland, Dublin, Ireland; ${ }^{2}$ Royal College of Physicians in Ireland, Dublin, Ireland; ${ }^{3}$ Children's University Hospital, Temple Street, Dublin, Ireland

\subsection{6/archdischild-2019-epa.604}

Aim To compare the opinion of paediatric consultants to paediatric Senior House Officer's (SHO's) with regards their perceived level of preparedness for starting clinical work in paediatrics.

Methods A 10 item five-point Likert scale questionnaire ( $1=$ strongly disagree, $5=$ strongly agree) was administered to paediatric consultants examining how well they felt their SHO was performing. A similar 10 item questionnaire was administered to current paediatric SHO's examining how well prepared they felt they were to perform in these areas when they commenced work in paediatrics.

There were 5 questions which appeared on both questionnaires and they relate to; procedures, clinical examination, teamwork, history taking and out-patient consultations.

Results 50 consultants completed the questionnaire and expressed satisfaction with all aspects of their SHO's performance. 75 SHO's completed the questionnaire and rated their undergraduate preparation for the job relatively poorly in the

Abstract P254 Table 1 Comparing responses by SHO to consultants for those question which appear on both the SHO and consultant satisfaction questionnaire using a Mann Whitney $\mathrm{U}$ test

\begin{tabular}{llll}
\hline Question & $\begin{array}{l}\text { Consultant } \\
\text { Median Likert } \\
\text { score }\end{array}$ & $\begin{array}{l}\text { SHO }(\mathrm{n}=75) \\
\text { Median likert } \\
\text { score }\end{array}$ & pValue \\
\hline Procedures & $4(n=46)$ & 2 & $<0.05$ \\
Clinical exam & $4(n=50)$ & 4 & 0.51 \\
Teamwork & $4(n=47)$ & 4 & $<0.05$ \\
History Taking & $4(n=36)$ & 4 & 0.15 \\
Out-patient work & $4(n=33)$ & 4 & $<0.05$ \\
\hline
\end{tabular}

